\title{
The design of IPT system for multiple kitchen appliances using class E LCCL circuit
}

\author{
N. X. Yin', S. Saat ${ }^{2}$, S. H. Husin ${ }^{3}$, Y. Yusop ${ }^{4}$, M. R. Awal ${ }^{5}$ \\ ${ }_{1,2,3,4}$ Centre for Telecommunication Research and Innovation (CeTRI), Faculty of Electronic and Computer Engineering, \\ Universiti Teknikal Malaysia Melaka, Malaysia \\ ${ }^{5}$ School of Ocean Engineering, Universiti Malaysia Terengganu (UMT), Malaysia
}

\begin{tabular}{l} 
Article Info \\
\hline Article history: \\
Received Jun 13, 2019 \\
Revised Jan 17, 2020 \\
Accepted Feb 2, 2020 \\
\hline
\end{tabular}

Keywords:

Class E inverter

Impedance matching

Inductive power transfer

Multiple kitchen appliances

Wireless power transfer

\begin{abstract}
Since many years ago, kitchen appliances are powered up by cable connected. This create a troublesome case as wire might tangle together and cause kitchen table messy. Due to this, wireless power technology (WPT) is introduced as its ability is to transmit power to load without physical contact. This leads to cordless solution better in safety as the product can be completely seal, highly expandable power range. This work focuses on the design of WPT based on inductive approach to power up multiple kitchen appliances. The selection of inductive approach over its partners capacitive and acoustic is mainly due to high power efficiency. Class E inverter is proposed here to convert the DC to AC current to drive the inductive link. A $1 \mathrm{MHz}$ operating frequency is used. To ensure the circuit is robust with load variations, an LCCL impedance matching is proposed. This solution is table to maintain the output power if there is a slight change in load impedance. Finally, the developed prototype is able to supply $50 \mathrm{~V}$ utput which can achieve power transmission up to $81.76 \%$.
\end{abstract}

Copyright $\left({ }_{0} 2020\right.$ Institute of Advanced Engineering and Science. All rights reserved.

\section{Corresponding Author:}

S. Saat,

Centre for Telecommunication Research and Innovation (CeTRI),

Faculty of Electronics and Computer Engineering,

Universiti Teknikal Malaysia Melaka,

Hang Tuah Jaya, 76100 Durian Tunggal, Melaka, Malaysia.

Email: shakir@utem.edu.my

\section{INTRODUCTION}

Nowadays, wireless power transfer (WPT) technology has become one of the top research areas for reliable applications, especially in low-power technology applications such as cell phone chargers, smart card systems, radio frequency identification (RFID), high-power electric vehicles (EV) and biomedical equipments [1-5]. WPT transfers power or energy from the power source to the power load through the medium without a connection line (physical contact) [1-3]. The WPT system will eliminate existing highvoltage transmission cables, towers and substations between power stations and consumers, as well as facilities interconnected by electrical technology plants worldwide [6]. WPT's advantages in cable elimination and maintenance-free operation are particularly helpful in kitchen applications to put aside the electronic kitchen appliances we use every day.

One of the popular WPT technology is based on capacitive coupling between transmitter and receiver. However, existence capacitor required high withstanding voltage along with the high capacitance value for a given output current which means that this kind of supply is only practical for high power applications [7, 8]. On the other hand, acoustic power transfer is comparatively new technology which optimizing sound waves vibration or ultrasonic propagate waves to convey energy wireless for power transmission. Although it is a light-based system but still able to supply a large amount of power. Unfortunately, its diffraction loss directly affects efficiency over far distance [9-11]. 
Due to the above mentioned issue, this work focuses on the inductive approach in order to transmit power to the multiple kitchen appliances. The method is also known as Inductive Power Transfer (IPT). IPT system offers several advantages, such as; 1. Ability of transmitting high-power transmission, 2. Can handle robustness load which mean mobility of multiple kitcen utensils shift around the table [12-14]. Although the APT could overcome power transmission and distance limitation but still the hardships of large acoustic mismatch of the transmitter and receiver with the medium could lead to a severe limit on the efficiency of power transfer. Hence, the inductive approach is preferable in this work.

Currently, in the commercial market induction cooker using direct induction heating of cooking vessels, rather than relying on indirect radiation, convection, or thermal conduction. Induction cooking allows high power and very rapid increases in temperature to be achieved, and changes in heat settings are instantaneous [15]. However, induction cooker only has limited two slots and mainly for cooking. Also, induction cooker could not be shifted from one location to another location easily. By utilizing IPT system, the power can be transferred to multiple kitchen appliances and enable to power up not only cooker but also boiler, fruit blender, mixer and others. Besides that, the kitchen load is shiftable around the kitchen table and this increases the flexibility on preparing food. Therefore, in this work wireless multiple kitchen appliances system is proposed using inductive approach.

\section{OVERVIEW OF THE PROPOSED IPT METHOD}

Figure 1 shows the proposed IPT system for this work. This prototype is designed to deliver high power (at least $50 \mathrm{~W}$ ) with the supply voltage up to $50 \mathrm{~V}$ and effective distance gap is $5 \mathrm{~cm}$. Mosfet driver is used to supply $5 \mathrm{~V}$ voltage to drive Mosfet in Class E Inverter circuit. IRFP250N Mosfet is used here as its able to switch at $1 \mathrm{MHz}$ frequency with $50 \%$ of duty cycle. High frequency switching allows power to be transfered in a short duration [16].

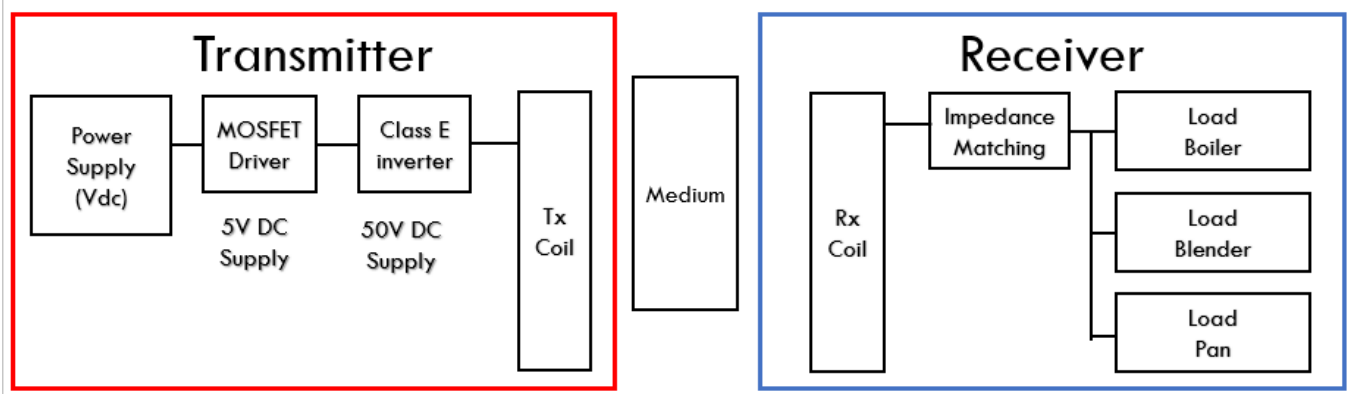

Figure 1. IPT system block diagram

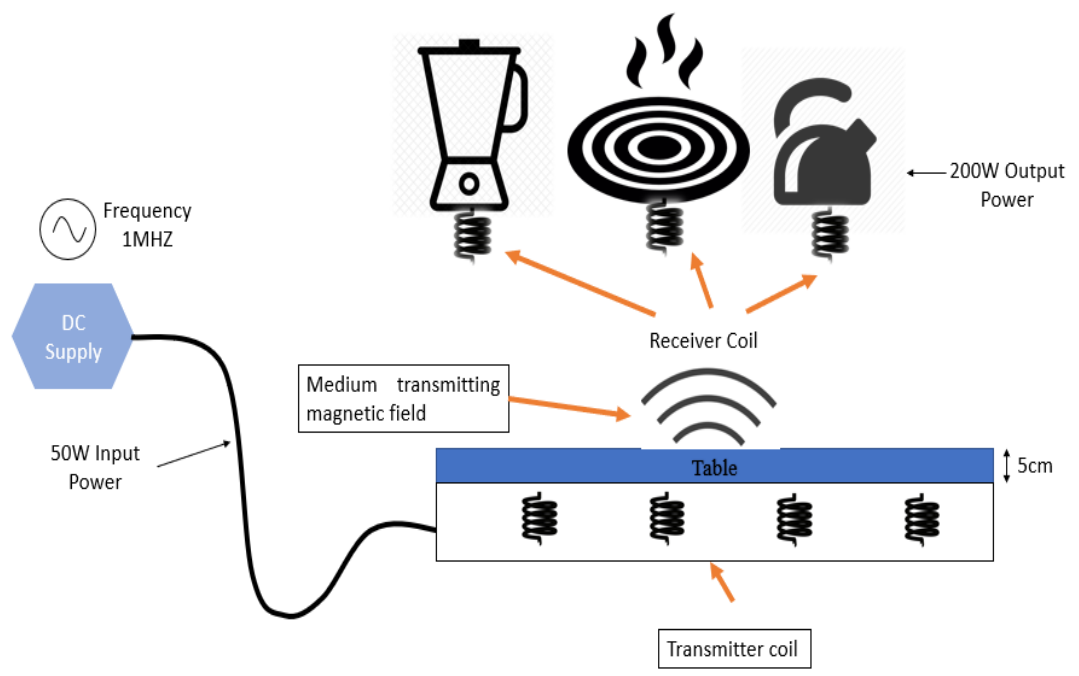

Figure 2. General overview of the project 
In IPT system, a high frequency current is desired to drive the magnetic field coupler so that the magnetic flux can flow through it to provide the load with the required power. Therefore, a Class-E inverter is designed as the high frequency inverter [17, 18] at the transmitter to convert DC source to AC. On the other hand, the problem of power loss during the transmission process is overcome by proposing LCCL impedance matching circuits at the receiver part. The overall illustration of the work is shown in Figure 2.

\section{METHODOLOGY}

The basic conceptual design of this prototype is shown in Figure 1 and Figure 2 respectively.

\subsection{Class e inverter design}

Class E Inverter is a well-known circuit implemented for high frequency applications [19]. The circuit has low switching losses with high frequency output which benefits to our proposed system. Basically, class E inverter is categorized as class E zero voltage switching (ZVS) inverter and the class E zero current switching (ZCS) inverter. The class E inverter circuit is shown in Figure 3.

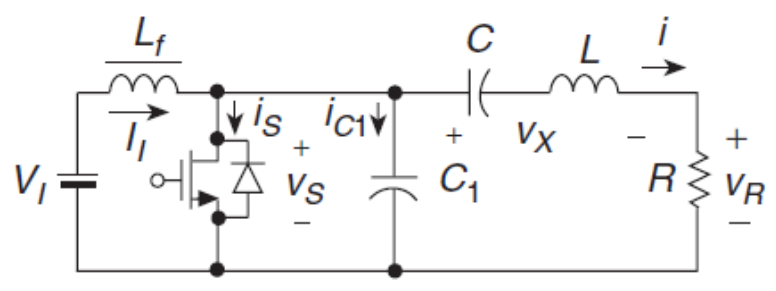

Figure 3. Class E circuit

The circuit consists of power MOSFET operating as a switch, L-C-R series-resonant circuit, shunt capacitor $\mathrm{C} 1$, and choke inductor Lf. The switch turns on and off at the operating frequency, $\mathrm{f}=\omega / 2 \pi$ which determined by a driver. Besides the low input of the MOSFET gate, $\mathrm{Vg}$. as the voltage drain, $\mathrm{Vd}$ should be three times greater than $\mathrm{Vg}$ to ensure the resonance tank not be burned. The resistor $\mathrm{R}$ is an ac load. The choke inductance Lf is assumed to be high enough so that the ac current ripple on the dc supply current I1 can be neglected. A small inductance with a large current ripple is also possible [20]. When the switch is $\mathrm{ON}$, the resonant circuit consists of $\mathrm{L}, \mathrm{C}$, and $\mathrm{R}$ because the capacitance $\mathrm{C} 1$ is short-circuited by the switch. However, when the switch is OFF, the resonant circuit consists of $\mathrm{C} 1, \mathrm{~L}, \mathrm{C}$, and $\mathrm{R}$ connected in series. Because $\mathrm{C} 1$ and $\mathrm{C}$ are connected in series, the equivalent capacitance is lower than $\mathrm{C}$ and $\mathrm{C} 1$. In the resonant tank circuit, there is an inductor series with capacitor then parallel with a capacitor. The value of the passive elements is decided according to the following equations:

The load resistance, $\mathrm{R}$ can be calculated as,

$$
\mathrm{R}=\frac{8}{\pi^{2}+4} \times \frac{V I}{P o}
$$

then, based on the proposed operating frequency, shunt capacitor, C1 and choke inductor, Lf can be calculated as follows [8]:

$$
\begin{aligned}
& \mathrm{C}_{1}=\frac{8}{\pi\left(\pi^{2}+4\right) \omega R} \\
& L_{f}=2\left(\frac{\pi^{2}}{4}+1\right) \frac{R}{f}
\end{aligned}
$$

the series capacitance, $\mathrm{C}$ and series resonant inductor, $\mathrm{L}$ are given as:

$$
\begin{aligned}
& C=\frac{1}{\omega R\left(Q_{L}-\frac{\pi\left(\pi^{2}-4\right)}{16}\right)} \\
& L=\frac{Q_{L} R}{W}
\end{aligned}
$$


Note that, Q is a Quality Factor that needs to be determined first. In this work, Q is 10 . This value is chosen so that the bandwidth obtained is sufficient enough for tuning purpose later to guanatee the ZVS condition of the circuit, see [10]for details.

\subsection{Impedance matching circuit}

Implementation of impedance matching is applied at receiver side in order to improve power efficiency [21, 22]. A $1 \mathrm{MHz}$ class E inverter circuit is implemented with series LC impedance matching at transmitter part [23]. Parallel topology CL part of impedance matching connected with the load in parallel topology is proposed at receiver side, so the resonante behavior will compensate the power being transfer [24]. This impedance matching circuit is known as LCCL topology [25], see Figure 4 for the scematic of the circuit. Based on simulation work, the perfect coupling factor is 0.2 with an effective distance gap of $5 \mathrm{~cm}$.
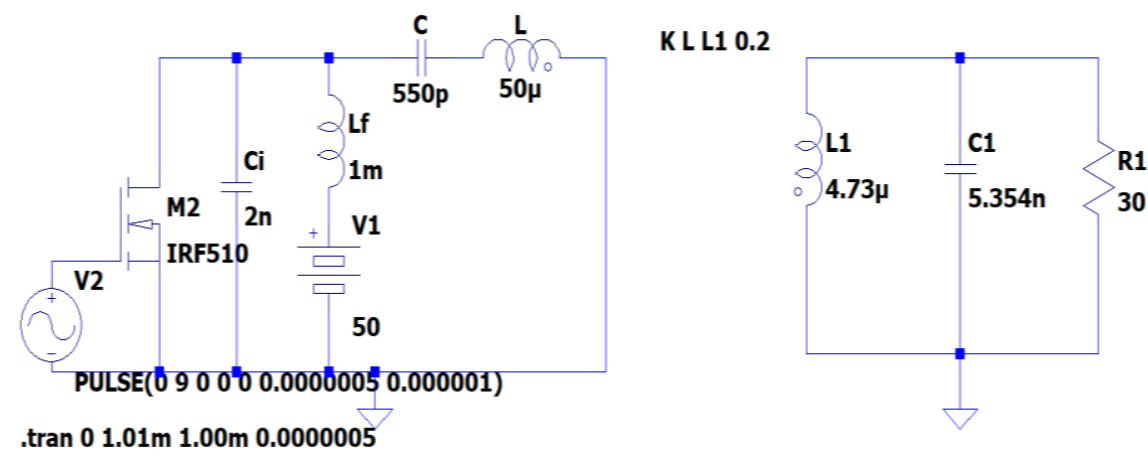

Figure 4. Scematic for LCCL impedance matching circuit

\subsection{Experimental work}

The transmitter circuit is designed on the PCB board then connect to the transmitter inductance coil. The transmitter circuit included class E inverter circuit with series LC of impedance matching. Receiver module are built into the load which underneath the boiler with sealed. The receiver circuit included receiver inductance coil connected to the parallel topology of CL impedance matching. Figure 5 and Figure 6 illustrates the experiment set up of the proposed system.

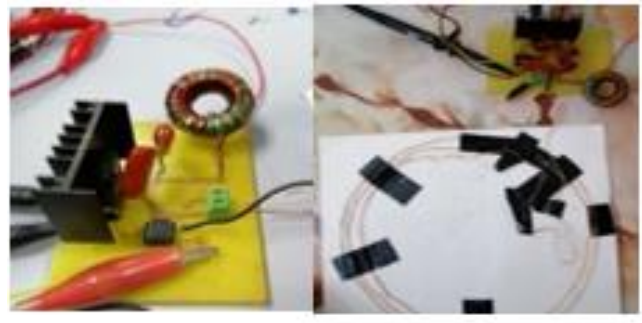

Figure 5. Transmitter side

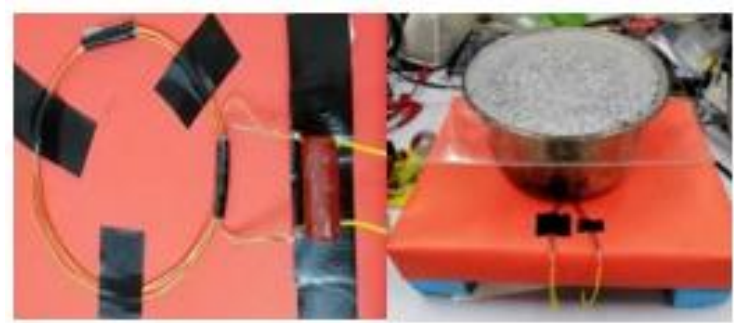

Figure 6. Receiver side

\section{RESULTS AND DISCUSSION}

Based on the desired output of class E inverter circuit, the value of components in resonant circuit is decided using the equation from (1) to (5) by using the values that are given in Table 1. All the calculated values are then tabulated in Table 2. In this class E inverter circuit, IRFP250N MOSFET is chosen because its low static Drain-to-Source On-Resistance, RDS and withstand high power dissipation, PD. Function generator generates square wave pulse and MOSFET driver is used to boost the square wave pulse to achieve minimum voltage required by the MOSFET. In addition, ZVS condition has to be considered to produce high power efficiency in class E circuit. Basically, the component values in the resonant circuit must be selected appropriately so that the switch will turn on at zero voltage. 
Table 1. Design specification for class E inverter circuit

\begin{tabular}{ll}
\hline Design Specification & Value \\
\hline Rated power, Pout & $50 \mathrm{~W}$ \\
Input voltage, Vi & $50 \mathrm{~V}$ \\
Duty cycle, D & $50 \%$ \\
Frequency ,f & $1 \mathrm{MHz}$ \\
Quality factor & 10 \\
\hline
\end{tabular}

Table 2. Class E inverter parameter

\begin{tabular}{ll}
\hline Design Specification & Value \\
\hline Choke Inductor, $\mathrm{R}_{\mathrm{f}}$ & $1 \mathrm{mH}$ \\
Shunt Capacitor, $\mathrm{C}_{\text {shunt }}$ & $2 \mathrm{nF}$ \\
Series Capacitor, $\mathrm{C}_{\text {tank }}$ & $550 \mathrm{pF}$ \\
Series inductance, $\mathrm{L}_{\text {tank }}$ & $50 \mu \mathrm{H}$ \\
$\mathrm{R}_{\text {load }}$ & $30 \Omega$ \\
\hline
\end{tabular}

Figure 7 displays the gate voltage and drain voltage which fulfilled ZVS condition of the simulation work. When the VG drops to zero the VD achieves 170V. This happens when MOSFET acts as open circuit. This definitely fulfills the characteristics of class E inverter itself which produces VD 3 times larger than the input voltage. Meanwhile, Figure 8 provides results for experimental work of class E inverter circuit. From the experimental results, $50 \mathrm{~V}$ dc supply and $1 \mathrm{MHz}$ resonant frequency the output ZVS waveform has been successfully achieved (with some distortion) and this is shown in Figure 8(a). For Figure 8(b), the green line is the output voltage at the load. The ouput from this output voltage will be then connected to the transmission coil.

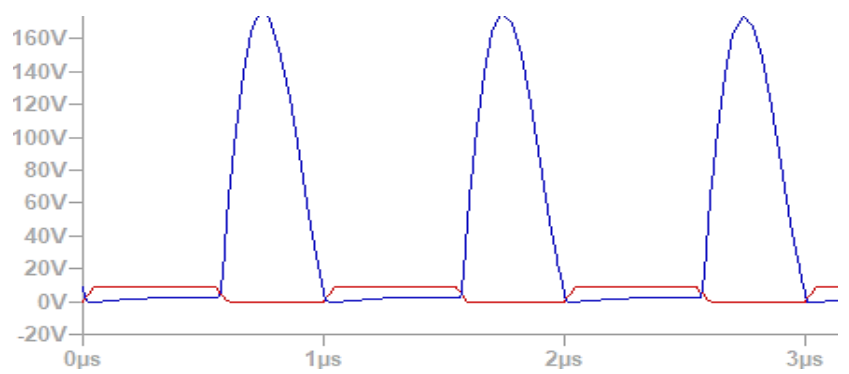

Figure 7. ZVS condition in class E circuit

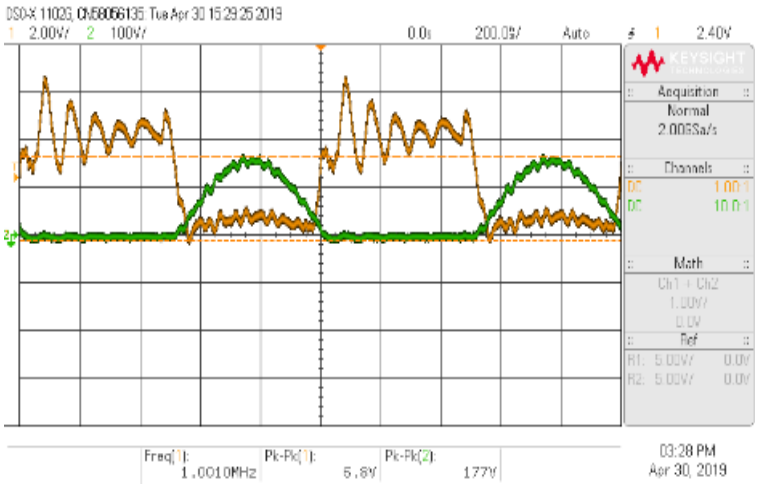

Figure 8(a). ZVS from oscilloscope

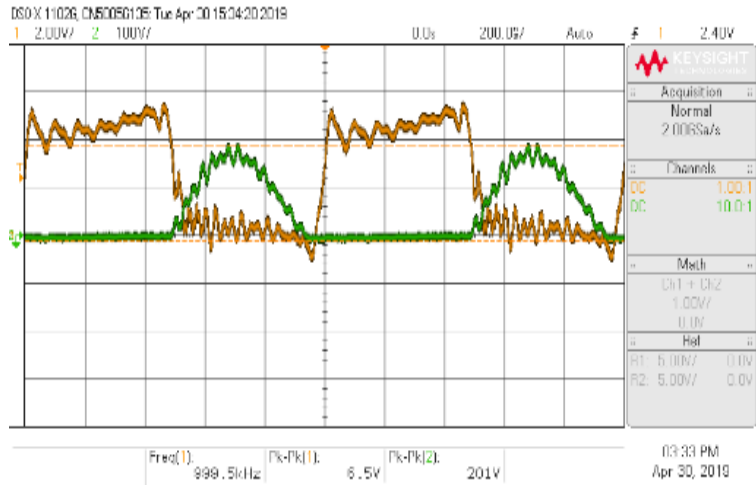

Figure 8(b). Drain voltage versus output voltage at load

\subsection{Analysis of impedance matching}

Independent class E circuit provides input power of $35.57 \mathrm{~W}$ and output power of $30.845 \mathrm{~W}$. The power efficiency here is $86.71 \%$. By proposing LCCL impedance matching circuit, the input power increases to $121.19 \mathrm{~W}$ and output power is $109.16 \mathrm{~W}$. The power efficiency is $90 \%$. In this system, kitchen 
appliances require high power to power up, hence impedance matching plays an important role to boost up the efficiency, so the output power. This is highlighted in Figures 9 and 10 correspondingly.

For the analysis purpose, we would like to study the impact of coupling variation to the circuit with and without impedance matching circuit. In this context the following parameters are made constant; At transmitter side: Cshunt $=2 \mathrm{nF}$, choke inductor $=1 \mathrm{mH}$, Ctank $=550 \mathrm{pF}$, Ltank $=50 \mathrm{uF}$, and input voltage $=50 \mathrm{~V}$. At receiver side, $\mathrm{L} 1=4.73 \mathrm{uF}$ and $\mathrm{C} 1=5.354 \mathrm{nF}$ and load $=300 \mathrm{ohm}$. The manipulated variable is coupling factor is varied from $0-1$. The responding variable is output power. We can see that the ouput power achieved the highest one with impedance matching circuit at 0.2 coupling factor. Meanwhile, highest ouput power without impedance happened at 0.4. Based on this it is obvious to us that applying impedance matching circuit allow one to transfer power at higher distance than without impedance matching circuit. Figure 11 explains this scenario where ouput power without impedance matching have shifted to right and achieved the same power at a nearer distance.

Figures 12-14 provides details results on the reason of coupling factor 0.2 gives the highest power output. It is obvious from Figure 13 that at 0.2 coupling factor, the ZVS is successfully achieved and leads to aprroximately switching loss. This will greatly increase the efficiency of such system. The overall comparison between the performance of the circuit with and without impedance matching with the variation of coupling factor is shown in Figure 15.

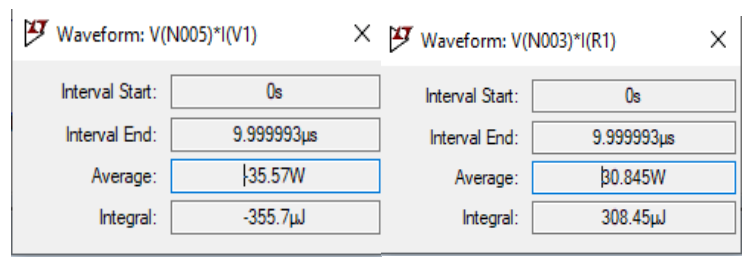

Figure 9. Class E circuit without impedance matching

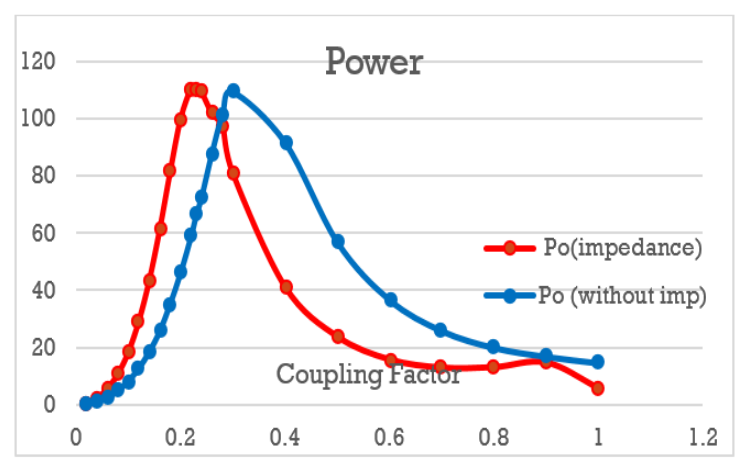

Figure 11. Power versus coupling factor

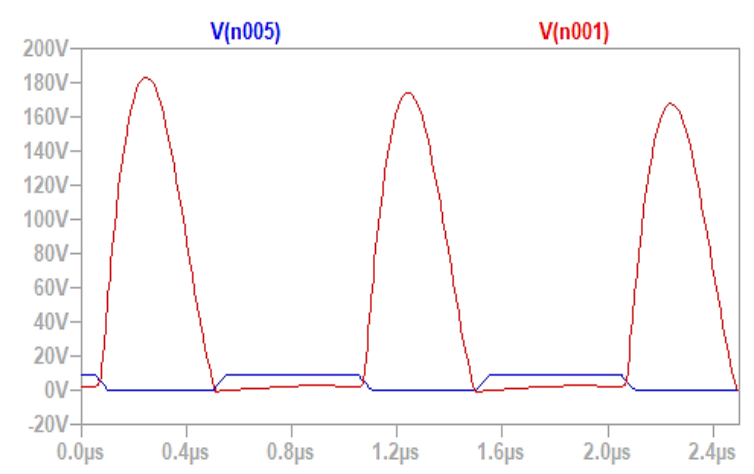

Figure 13. ZVS condition at coupling factor of 0.2

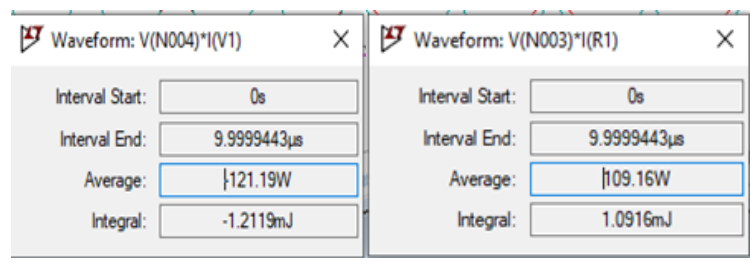

Figure 10. Class E circuit with impedance matching

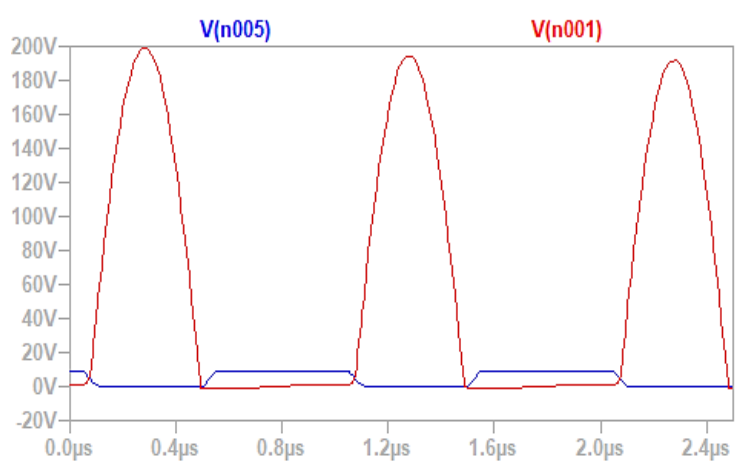

Figure 12. ZVS condition at coupling factor of 0.1

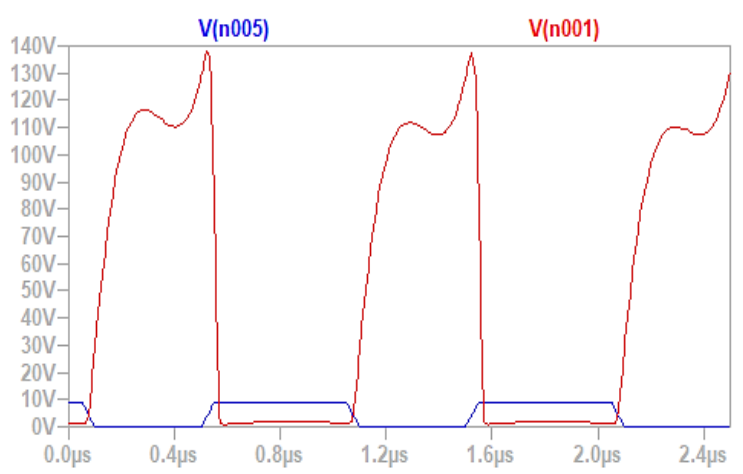

Figure 14. ZVS condition at coupling factor of 0.3 


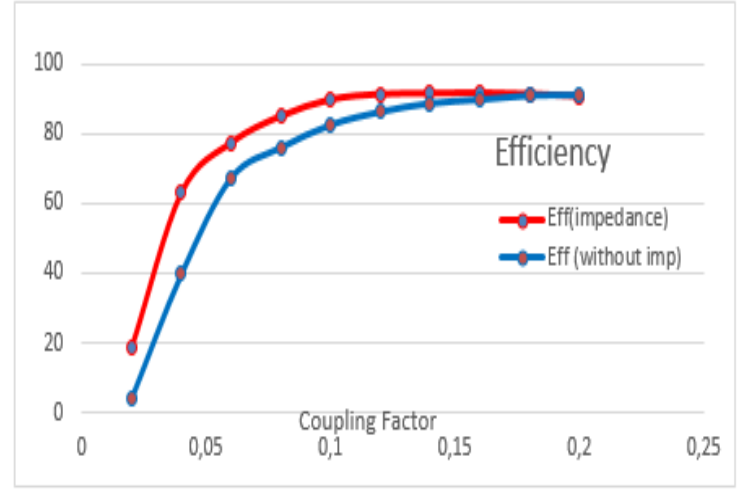

Figure 15. Power efficiency versus coupling factor with and without impedance matching

\subsection{Prototype development}

The protype of the work is shown in Figure 16. Three loads are used here, namely, LED light, stove and fruits blender. The proposed IPT system is able to power up loads successfully. In this context, the kitchen light was lighted up, the fruit blender is spinned and the boiler has boiled during power transmission. By suppling 50VDC to the transmitter part, the class E inverter converts DC source to AC source. This is achievable by locating the receiver part at the effective area. The system able to deliver $72 \mathrm{~W}$ output power to power up the kitchen appliances with $81.76 \%$ of power efficiency

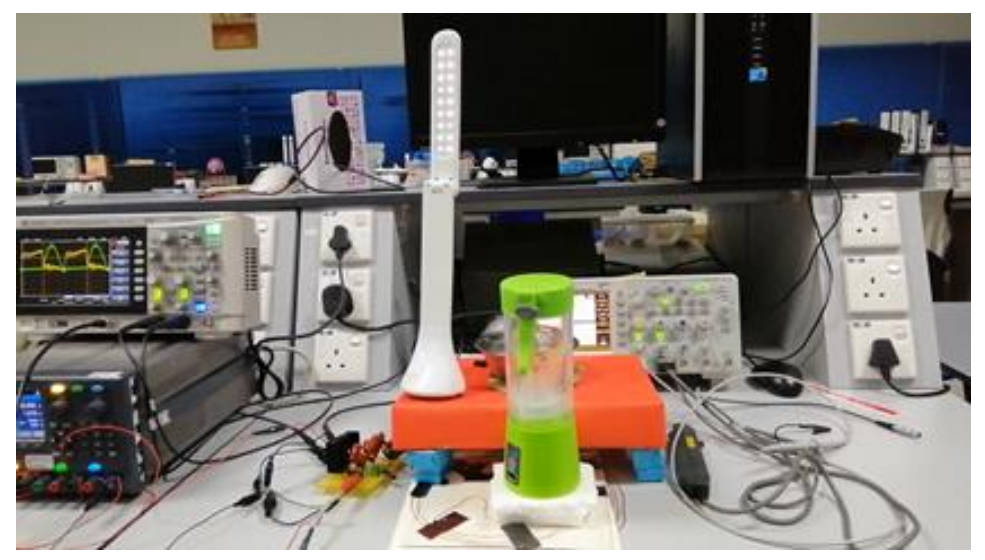

Figure 16. Complete prototype of the proposed method

\section{CONCLUSION}

In conclusion, the project had achieved the objectives of designing and developing the high efficiency resonant class $\mathrm{E}$ inverter circuit. The class $\mathrm{E}$ inverter circuit is successfully constructed in simulation and implemented in practical. The efficiency achieved for simulation is $90.07 \%$ while experimental result achieved $81.76 \%$. Additionally, the objective on designing impedance matching circuit by using parallel configuration topology had improved the power efficiency of the system from $86.71 \%$ to $90 \%$ for a gap distance of $5 \mathrm{~cm}$. The future works are; 1 . The safety module at the receiver side has to be designed so that load can be protected 2. The auto tuning circuit needs to be introduced to ensure the effectiveness of the proposed system although at misalignment condition.

\section{ACKNOWLEDGEMENTS}

We would like to express our gratitude to Universiti Teknikal Malaysia Melaka and Ministry of Education Malaysia for sponsoring this work under Fundamental Research Grant Scheme (FRGS/1/2016/TK04/FKEKK-Cetri/F00313). 


\section{REFERENCES}

[1] Y. Yusop, S. Saat, S. K. Nguang, H. Husin, and Z. Ghani, "Design of Capacitive Power Transfer Using a Class-E Resonant Inverter," in Journal of power electronics, vol. 16, no. 5, pp. 1678-1688, September 2016.

[2] H. Xueliang, T. Linlin, C. Zhong, Q. Hao, Z. Yalong, Wang Wei and C. Weijie, "Review and Research Progress on Wireless Power Transfer Technology," in Diangong Jishu Xuebao/Transactions of China Electrotechnical Society, vol. 28, no. 10, pp. 1-11, October 2013.

[3] A. M. Jawad, R. Nordin, S. K. Ghargan, H. M. Jawad and M. Ismail, "Opportunities and Challenges for Near-Field Wireless Power Transfer: A Review,” in Energies, vol. 10, no. 7, pp. 1022, July 2017.

[4] Je-Dok Kim, Chuanbowen Sun, and In-Soo Suh, "A proposal on wireless power transfer for medical implantable applications based on reviews," 2014 IEEE Wireless Power Transfer Conference, Jeju, pp. 166-169, 2014.

[5] F. Lu, H. Zhang and C. Mi, "A Review on the Recent Development of Capacitive Wireless Power Transfer Technology," in Energies, vol. 10, no. 11, pp. 1752, November 2017.

[6] C. Liu, A. P. Hu, G. A. Covic, and N. K. C. Nair, "Comparative study of CCPT systems with two different inductor tuning positions," in IEEE Transactions on Power Electronics, vol. 27, no. 1, pp. 294-306, Jan. 2012.

[7] J. Dai and D. C. Ludois, "Single active switch power electronics for kilowatt scale capacitive power transfer," in IEEE Journal of Emerging and Selected Topics in Power Electronics, vol. 3, no. 1, pp. 315-323, March 2015.

[8] Y. Yusop, S. Saat, S. K. Nguang, H. Husin, and Z. Ghani, “A Four-Plate Compact Capacitive Coupler Design and LCL-Compensated Topology for Capacitive Power Transfer in Electric Vehicle Charging Application," in IEEE Transactions on Power Electronics, vol. 31, no. 12, pp. 8541-8551, Dec. 2016.

[9] T. Zaid, S. Saat, Y. Yusop, and N. Jamal, "Contactless energy transfer using acoustic approach - A review," 2014 International Conference on Computer, Communications, and Control Technology (I4CT), Langkawi, pp. 376-381, 2014.

[10] M. P. Kazmierkowski and A. J. Moradewicz, "Unplugged but connected: Review of contactless energy transfer systems," in IEEE Industrial Electronics Magazine, vol. 6, no. 4, pp. 47-55, Dec. 2012.

[11] H. Basaeri, D. B. Christensen, and S. Roundy, "A review of acoustic power transfer for bio-medical implants," in Smart Materials and Structures, vol. 25, no. 12, pp. 123001, December 2016.

[12] S. Assawaworrarit, X. Yu, and S. Fan, "Robust wireless power transfer using a nonlinear parity-time-symmetric circuit," in Nature, vol. 546, no. 7658, pp. 387-390, June 2017.

[13] K. A. Kalwar, M. Aamir, and S. Mekhilef, "Inductively coupled power transfer (ICPT) for electric vehicle charging - A review," in Renewable and Sustainable Energy Reviews, vol. 47, pp. 462-475, July 2015.

[14] K. Aditya, S. Sheldon and S. Williamson, "Design considerations for loosely coupled inductive power transfer (IPT) system for electric vehicle battery charging - A comprehensive review," 2014 IEEE Transportation Electrification Conference and Expo (ITEC), Dearborn, MI, pp. 1-6, 2014.

[15] M. Sweeney, J. Dols, B. Fortenbery, and F. Sharp, "Induction Cooking Technology Design and Assessment," in 2014 ACEEE Summer Study on Energy Efficiency in Buildings, pp. 370-379, 2014.

[16] C. Sen Wang, G. A. Covic, and O. H. Stielau, "Power Transfer Capability and Bifurcation Phenomena of Loosely Coupled Inductive Power Transfer Systems," in IEEE Transactions on Industrial Electronics, vol. 51, no. 1, pp. 148-157, Feb. 2004.

[17] Y. Yusop, H. Husin, S. Saat, S. K. Nguang, and Z. Ghani, "Class-E LCCL for capacitive power transfer system," 2016 IEEE International Conference on Power and Energy (PECon), Melaka, pp. 428-433, 2016.

[18] Y. Yusop, S. Saat, S. K. Nguang, H. Husin, and Z. Ghani, "Maximizing DC-to-Load Efficiency for Inductive Power Transfer," in IEEE Transactions on Power Electronics, vol. 28, no. 5, pp. 2437-2447, May 2013.

[19] W. Chen, R. A. Chinga, S. Yoshida, and J. Lin, "A 25.6 W $13.56 \mathrm{MHz}$ wireless power transfer system with a $94 \%$ efficiency GaN Class-E power amplifier," 2012 IEEE/MTT-S International Microwave Symposium Digest, Montreal, QC, pp. 1-3, 2012.

[20] M. Liu, M. Fu and C. Ma, "Parameter Design for a 6.78-MHz Wireless Power Transfer System Based on Analytical Derivation of Class E Current-Driven Rectifier," in IEEE Transactions on Power Electronics, vol. 31, no. 6, pp. 4280-4291, June 2016.

[21] M. Kazimierczuk, "Collector Amplitude Modulation of the Class E Tuned Power Amplifier," in IEEE Transactions on Circuits and Systems, vol. 31, no. 6, pp. 543-549, June 1984.

[22] W. Z. Chen, W. H. Chen, and K. C. Hsu, "Three-dimensional fully symmetric inductors, transformer, and balun in CMOS technology," in IEEE Transactions on Circuits and Systems I: Regular Papers, vol. 54, no. 7, pp. 14131423, July 2007.

[23] M. Lapinoja and T. Rahkonen, "An active tuning and impedance matching element," 1998 IEEE International Symposium on Circuits and Systems (ISCAS), Monterey, CA, vol. 1, pp. 559-562, 1998.

[24] N. Jamal, S. Saat, and A. Z. Shukor, "A study on performances of different compensation topologies for loosely coupled inductive power transfer system," 2013 IEEE International Conference on Control System, Computing and Engineering, Mindeb, pp. 173-178, 2013.

[25] S. Samanta, A. K. Rathore, and D. J. Thrimawithana, "Bidirectional Current-Fed Half-Bridge (C) (LC)-(LC) Configuration for Inductive Wireless Power Transfer System," in IEEE Transactions on Industry Applications, vol. 53, no. 4, pp. 4053-4062, July-Aug. 2017. 


\section{BIOGRAPHIES OF AUTHORS}
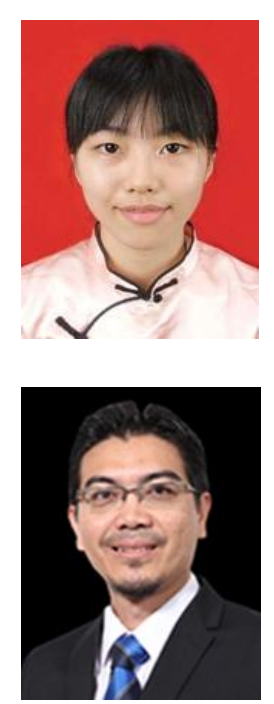

Shakir Saat obtained his B.Eng and Master in Electrical Engineering from UTM in 2002 and 2006, respectively. Then, he obtained his $\mathrm{PhD}$ from The University of Auckland in the field of nonlinear control theory in 2013. He is now an Associate Professor and Dean of Faculty of Electronic and Computer Engineering, Universiti Teknikal Malaysia Melaka. His research interest is on nonlinear systems control theory and wireless power transfer technologies. He has published one monograph (published by Springer Verlag) on polynomial control systems and many journals and conference papers and mostly published in the high quality journal such as International Journal of Robust and Nonlinear Control, and IET Control.

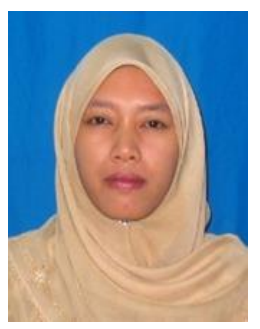

Yusmarnita Yusop was born in Melaka, Malaysia in 1979. She received the B. Eng in Electrical Engineering (Mechatronic) from Universiti Teknologi Malaysia, in 2001, the M. Eng degree in Electrical Engineering from Kolej Universiti Tun Hussein Onn, Malaysia, in 2004 and Ph. D degree in Electrical Engineering (Capacitive Power Transfer) from Universiti Teknikal Malaysia Melaka in 2018. Her career as academician begins in 2005 as a Teachhing Engineer at Department of Industrial Electronic, Technical University Malaysia Malacca and now she is a Senior Lecturer at the same university. Her area of research interests includes electronic system design, wireless power transfer and power electronics.

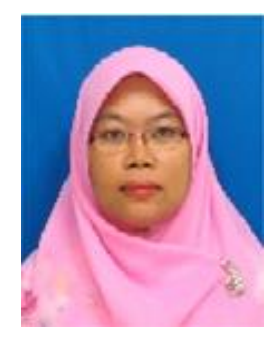

Siti Huzaimah Husin received the B.Eng (2000) from Multimedia University, M.Eng (2005) from Kolej Universiti Tun Hussein Onn, Malaysia respectively. First appointed as Engineering Instructor (2001) at Kolej Universiti Teknikal Malaysia Melaka and promoted as Lecturer (2005) and Senior Lecturer (2008) in the Department of Industrial Electronics, Faculty of Electronic and Computer Engineering at Universiti Teknikal Malaysia Melaka. Since September 2014, she is pursuing PhD in Advanced Control Technology that focused on acoustics energy transfer.

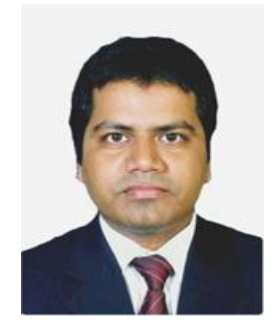

Md Rabiul Awal is currently working with School of Ocean Engineering, Universiti Malaysia Terengganu (UMT) as a lecturer. He has received his $\mathrm{PhD}$ in Communication Engineering from Universiti Malaysia Perlis (UniMAP), Malaysia, in 2018. He was awarded Master in Computer Science from International Islamic University Malaysia (IIUM), Malaysia and the B.Sc. in Electrical \& Electronics Engineering from International Islamic University Chittagong (IIUC), Bangladesh and in 2015 and 2011 respectively. From 2011 to 2012, he worked as a RF Engineer in 3S Network (BD) Ltd. and from 2013 to 2015 he worked as research assistant in IIUM and UniMAP. His research interests include underwater communications, wireless power transfer and energy harvesting. 